\title{
Water and Society
}

ABEL WOLMAN, Dr.Eng.

$I^{\mathrm{N}}$

$\mathrm{N}$ the United States, blessed with reasonably comprehensive water services, the public health implications of water supply have become less and less dramatic because of the almost total elimination of the familiar waterborne diseases of the early 20 th century. The disappearance of typhoid fever and other enteric diseases in much of the Western World has resulted in a declining interest of most health workers in the field of water supply.

In this favorable environment, however, the provision of water service in expanding urban areas remains one of the major problems of society. So accustomed have our citizens become to unlimited amounts of excellent quality water that they assume, from past experience, that their requests for this service will be met automatically by private and public enterprise. This assumption, however, is not supported by the results. In some parts of the Western World, due to natural causes and to unprecedented urbanization, rationing of water is almost universal and continuous.

When we move out of the Western World the situation has few favorable characteristics. More than three-quarters of the total population of the world lacks true community water service and few have water of high quality. Comprehensive communal water systems which either reach into the house or are adjacent to the place of living are virtually unknown in vast areas. The consequent toll in waterborne disease is characteristic of western experience in the late 19 th century.

\section{Resources in Selected Areas}

In the United States in 1954, the total withdrawals from streamflow for irrigation, mining, manufacturing, steam electric power, and municipal water supplies was somewhat over 300 billion gallons per day. By 1980 this amount will approach some 560 billion gallons per day.

Before these astronomical figures cause too much alarm it should be emphasized that, with the exception of irrigation uses, a large part of these withdrawals are returned to the streams. A more informative set of figures, therefore, would indicate that the actual consumption of water will rise in the United States, from 110 billion gallons per day in 1954 to 120 billion in 1980 . It is heartening to remember also that in these 2 years consumption represents only some 10 to 11 percent of the average streamflows.

Water availability is a function of place, time, and climate. Average figures obviously do not disclose that some areas of the United States will encounter water difficulties earlier and to a greater degree than others. It is extremely doubtful, however, that scarcity of water, at least in the United States, will impose a serious restriction on growth now or in the remote future.

Greater attention to the art of management of water resources is increasingly in prospect, simply because the ease and accessibility of development will decrease while costs increase.

Even in the United States, health officials must return to a daily detailed interest and responsibility for water service, because no other group is likely to make itself responsible for water requirements of communities. His-

Dr. Wolman is professor of sanitary engineering, emeritus, at Johns Hopkins University, Baltimore. This paper was presented at the Seventh Annual Meeting of the American College of Preventive Medicine in San Francisco, November 1960. 
torically, the health officer dominated this area of development, initially for public health reasons and later by virtue of experience in the planning of community water facilities. He must resume this responsibility.

When one turns from the United States, the assessment of water service becomes relatively bleak.

In Central and South America some 100 million people do not have water service at their homes. At the rate at which new water facilities are being built, they will neither meet the enormous backlog of deficiency nor even keep pace with the annual increase in population. Since 1950, for example, an additional 21 million people have been supplied with water, while the population has simultaneously increased by 30 million. If this trend should continue until 1980, probably over 150 million people will lack adequate water services in that year. In these and in many other countries water service not only lags behind population increase, but with each passing year their govermments fall further and further behind in installations.

The problem is intensified by the worldwide phenomena of urbanization and industrialization, which subject more and more people to conditions of living far more hazardous than those which prevailed in scattered rural areas. Venezuela is an interesting example of this international trend. In 1943 some 23 percent of the population of this country lived in concentrations of 5,000 inhabitants or more. In 1959 the figure had risen to 62 percent, and by 1980 it undoubtedly will exceed 70 percent. The percentage of population in Venezuela without water facilities, in aggregates of 5,000 or more, has now reached 50. Unless construction is very much greater than is now indicated, the population without water in 1980 may far exceed 50 percent for the urban areas.

Emphasis on development in urban areas is justified only because faster progress is possible and a greater coverage of people may result from a minimum of effort. That one cannot neglect smaller communities and strictly rural areas, because of political and humanitarian reasons, is a foregone conclusion. The magnitude of the water problems in these areas staggers the imagination.
Mexico is a case in point. That country has 24 communities of over 50,000 population; 135 of 10,000 to 50,000 , and 824 of 2,500 to 10,000 . The number of communities of less than 2,500 is 97,607. Exclusive attention to these small aggregates, as is the case in many countries, undoubtedly will require 75 to 100 years with a net benefit to only a small part of the total population.

Water service in the Near, Middle, and Far East is generally characterized by inadequate quantity, unsatisfactory quality, discontinuity of service, and inaccessibility to many houses, usually those of the poor.

In India the Government has made valiant efforts since 1954 to provide water supply and sanitary facilities. Its progress though significant is still disheartening. In its rural schemes it had provided facilities by 1960 to only a small fraction of the vast total number of villages awaiting service. In urban areas it has provided aid in hundreds of enterprises. The total expenditures, however, for both rural and urban water supply and sanitation projects is pathetically small in comparison with the enormous backlog of necessities and the rapid growth of population.

\section{Implications of Water Availability}

For years the sanitarian has emphasized both in thought and in action the high significance of the quality of water for the protection of man. Aside from a few countries, this philosophy has taken the turn of attempting to provide water in tiny quantities, but of good quality, at least at its origin. This action rested upon the sound, but limited, assumption that drops of good water would have high impact upon disease. Many of the hopes in such a philosophy have not materialized. Something more than good quality is essential to the preservation of health. To most fieldworkers it has become equally clear that several liters of water carried from some central point to a place of domiciliary use and storage all too often results in a quality deterioration at the home. The assumption that water of good quality at the source is synonymous with water of good quality at the point of human intake is not borne out by studies of actual household practice. 
In addition, it is increasingly clear that disease is related to water quantity nearly as much as it is to water quality. It is an insult to people to preach body cleanliness and a clean home, when they must carry water over long distances and at great sacrifices of time and energy. To ask an individual to maintain total cleanliness, while at the same time failing to provide adequate water quantities, hardly falls within the realm of sound public health education.

Much of the world is plagued by diseases in which water of poor quality plays a significant part. The diarrheal diseases of infants, young children, and adolescents are still the major cause of morbidity and mortality. More than 25 percent of the hospital beds of the world are estimated to be occupied by people ill because of poor water.

In many urban areas in Asia, cholera incidence would be materially reduced by the provision of safe and adequate water to many of the poverty stricken sections which are densely populated and continuously exposed to contaminated waters. In the Calcutta region, generally accepted as one of the major endemic foci of cholera in Asia, life in the bustees is a daily invitation to transmission of cholera and of other waterborne diseases. Significant reduction of these waterborne diseases awaits the provision of an ample quantity of safe water, close to the houses, in order to place cleanliness within the grasp of people.

There is good reason to believe that the persistence of typhoid fever, trachoma, yaws, bilharziasis, and other diseases is significantly related to the nonavailability of safe water in ample quantity.

Dr. C. J. Hackett, the medical officer in charge of venereal diseases and treponematoses of the World Health Organization Headquarters, made the pertinent comment, "It is at least suggestive that one of the main factors reducing yaws prevalence may be more water and more soap.

"A great reduction in the prevalence of yaws not attributable to a mass treatment campaign is usually accompanied by other changes that have contributed to the raising of the standard of living. The more obvious of these are more and better clothing; more bicycles on the roads; more village schools and more secondary school places; more dams, boreholes, and wells available and in use; and more soap-all of which are signs that the community is wealthier. However, village houses may be in no better state of repair, and excreta disposal may still remain a matter of individual action."

This disease, as so many other water "related" diseases, tends to decline as the total standard of living of a community rises.

The renewed emphasis on personal hygiene brings to mind the insistence of the late Professor Winslow on the importance of this factor in the transmission of many communicable diseases.

We have perhaps not yet scratched the surface of the significance of personal hygiene in relation to many of the diseases of modern society. In Louisiana, the transmission of poliomyelitis from vaccinated persons to household contacts was much more frequent in low socioeconomic groups than among those in which hygiene was better ( 51 percent of household contacts infected in the low socioeconomic group compared with 8 percent in the latter). A similar observation on the poliovirus has been made in the Belgian Congo, where overcrowding and poor hygiene favor the passage of the virus from one child to another. These situations of course, are highly complicated, both in the understanding of the behavior of the virus and in relating environment to these phenomena. In fact, under certain conditions, paradoxes arise between cleanliness, low-level hygiene, and poliomyelitis.

Recently in England, Dr. A. Leslie Banks commented on the relationship of cleanliness to incidence of dermatoses. His article, "Ecology in Relation to Dermatology," presents one of the few attempts to trace the history of skin diseases over the last 100 years or more. His observation is pertinent to a discussion on water-related diseases: "Indeed it is difficult to see how a healthy skin could be maintained in the absence of facilities for cleanliness and well-being." He gives as interesting examples the great decline in England of cases of impetigo and of verminous school children. In 1908 approximately one-half of the girls in urban areas were verminous; in rural areas about onequarter. In 1951 this figure had dropped to 
6 percent of the entire school population. The experience with ringworm was similar. In the early years of the school medical service ringworm was one of its greatest problems. In 1951 only 2,365 school children in England and Wales had ringworm of the scalp. The incidence of scabies in school children had declined from 38,000 cases in 1947 to 4,723 in 1951 .

In many of the environmental diseases it is, of course, true that measures other than the provision of water are jointly essential. For many of the intestinal diseases of the world multiple preventive measures would be productive. Mass treatment campaigns with modern atoxic anthelmintic products are indicated. Unfortunately, their success requires repetitive programs. If these are unaccompanied by opportunities for detailed personal cleanliness and broad hygienic living, their repetitive character becomes both permanent and costly.

Many of these considerations are strangely reminiscent of the Mills-Reinke phenomena noted in the early 20 th century, when these investigators attributed to improved water service a decline in water-associated, not true waterborne, diseases. Probably the phenomena which they were statistically measuring were those reflecting the opportunities for cleanliness and personal hygiene resulting from ample quantities of safe water.

So far little or no comment has been made on the high significance of water availability in relation to factors other than frank disease. In an era of rapid urbanization and industrialization, both in developed and developing countries, water must play a dominant part. The documentation of the economic impact of water is just being initiated. Such a record is desirable, if for no other reason than to justify the advantages of providing water for expanding populations, whereby vital commerce and industry may progress. Whether privately obtained or publicly developed, most modern industry requires water and in some instances of increasingly higher quality than that provided for human consumption. This trend will be intensified as the complexity and competitive character of manufacturing proceed. Even in a heavy industry such as steelmaking, a high quality of water is increasingly required. This demand has long been met by the synthetic rubber, the synthetic fiber, and the organic chemical industries.

The bare physiological requirements for water have profound significance in space technology, in general military problems, and under the most severe conditions of life in desert areas, but this minimum amount in liters will no longer satisfy the communities with which the practitioner must now deal. Planning water systems for people will not be based on the limited assumptions of the late 19th and early 20th centuries of 6 to 10 gallons per capita per day. Such meager provision ignores the effects and the requirements of urban and industrial life and the necessities of total cleanliness. It is unrealistic for the water needs of 1970 and 1980.

In the United States the requirement for industry and commerce in communities of over 10,000 people is generally more than half of the total water consumption. Furthermore, the amount of water essential for firefighting purposes in many instances dominates the size and cost of American water systems.

Where such a system amply provides for fire protection, the savings in annual fire insurance rates often are equal to the interest and amortization of the bond issue for constructing the facility. This fact is a more impressive argument for the installation of a public water system than is inherent in the prevention of disease. The monetary values are easily demonstrable and hence profoundly convincing to authorities and to citizens.

Too often, in many developing countries, housing projects have remained empty or have not been constructed and agricultural development has been delayed because of serious water deficiency.

These observations might be elaborated tenfold if time were afforded. They all point, however, to the fact that, without water, civilization dies. The late limnologist, Dr. August Thienemann, aptly phrased the theme of this paper in these terms: "Ohne Wasser, Kein Leben ; Ohne Wasser, Keine Kultur."

\section{Financial Aspects}

If every country in the world is or will be confronted with the necessity of providing water, the problem of how to proceed at once 
confronts the practitioner. The provision of water on any community basis, with even the most modest design and construction criteria, requires money. The money inherent in such systems looms large in terms of capital investment. Without burdening this paper with detailed estimates, it may be said that these requirements for money on a worldwide basis will run into many billions of dollars. This one fact staggers the health official, accustomed to annual budgets of relatively small and intelligible amounts.

It is of great importance, therefore, to stress the fact that large amounts of capital money for the purposes discussed here will be relatively small amounts on a per capita basis and still smaller on the basis of annual charges.

No major capital investment would be made in any country for any purpose if the amount were to be repaid in a single year. In functions other than water supply the man on the street is unaware of the investment required. When he enters a bus he does not mentally conjure up the cost of the bus or of the total transport system. When he turns on his electric bulb he is equally unaware of these facts. In community water systems, however, the first item which startles the official, as well as the private individual, is the amount of capital required to construct a system.

Part of this psychological response is due to the practice of constructing systems by central government grants or loans, or international gifts where the amounts are repayable in 5 years or less. These practices have resulted in excessive emphasis upon the initial capital investment, with little or no consideration of repayment on the basis of annual fixed charges over a minimum period of some 20 to 25 years. Per- sistent emphasis on initial investment will continue as long as central government remains the financial source for increasing numbers of public functions. In one such country 25 years ago, only 3 activities were dominantly supported by the central government; almost 30 functions receive support at present.

One of the first efforts, therefore, should be to develop the fiscal programing on a sound, selfsupporting basis, with long-term repayment of capital costs by annual charges against the water user. If and when such principles are adopted, financing of water systems enters the open market with all of the advantages which accrue from such sources of money.

In the United States some 19,000 public water systems have been financed throughout their history on a self-supporting basis. They supply over 125 million people. Without such responsible local financing this result could never have been obtained.

The lessons from this experience of almost 100 years must be adapted to other countries, so universally tied to central government largesse. These adaptations, of course, should be made in the light of the political structures, the cultural history, and the economic practices of the countries concerned. Cultural resistance to a modification of a "free water" concept is frequently suggested as a reason for retarded progress. This is contradictory to the many departures from such principles now successfully operating in almost every country of the world. Almost without exception, these successful departures in utility financing have been due to the high imagination and the courage of the citizens who recognized the obstacles inherent in history and hurdled them by the introduction of new practical and flexible schemes of finance. 